\title{
Results from a Study for Teaching Human Body Systems to Primary School Students Using Tablets
}

\author{
Emmanuel Fokides and Aikaterini Mastrokoukou \\ University of the Aegean, Greece
}

Received: 11.10.2017

Accepted: 23.03 .2018

Published: 13.04.2018

\begin{abstract}
The paper presents the results from a study which examined whether tablets together with a mobile application with augmented reality features can help students to better understand the functions of the respiratory and the circulatory system. The target group was 75 sixth-grade primary school students, divided into three groups. The first group was taught conventionally; students studied using a printed handbook. In the second, a constructivist teaching model was used, but the instruction was not technologically enhanced. The third group of students used tablets and an application, and the teaching was based on a slightly modified version of Bybee's 5Es model. All three groups of students worked in pairs, they were taught the same learning material, and the teacher acted as a facilitator of the process. Data were collected by means of a questionnaire and evaluation sheets. Results indicated that students in the third group outperformed students in the other two groups. The results can be attributed to students' enjoyment, motivation, and positive attitude towards the use of tablets as well as to the teaching method. The study's implications are also discussed.
\end{abstract}

Keywords: Augmented reality; Circulatory system; Mobile applications; Respiratory system; Tablet computers

\section{Introduction}

The teaching of many courses and in all levels of education changes and adapts according to the prevailing trends and methods. A driving factor for these changes is technology; its impact on education is such, that lead many researchers to believe that it holds, nowadays, a key instructional role. The above also applies to the teaching of science courses. According to a multitude of research projects, to the contemporary learning theories, and to the up-to-date instructional methods, diverse ICT tools have the potential to contribute to the better understanding and visualization of ideas and phenomena, which, in turn, lead to the better understanding of complex scientific concepts.

Portable devices, such as smartphones and tablets are among these tools. A significant body of the literature suggested that the integration of portable devices in education brings several benefits to students. Besides the positive learning outcomes (Wilkinson \& Barter, 2016), students become actively engaged in the learning process (Mang \& Wardley, 2013) and they develop positive attitudes towards learning (Gorhan, Oncu \& Senturk 2014). An impact on their critical thinking and creativity was also reported (Wilkinson \& Barter, 2016). However, others pointed out that the use of portable devices in teaching/learning still has a relatively 
undeveloped pedagogy and that the matter needs further examination (Haßler, Major, \& Hennessy, 2015).

Focusing on the teaching of science courses in primary education, they are regarded as challenging for both teachers and students. Indeed, in many cases, teachers revert to conventional instruction because of the problems they have in understanding a number of subjects (Mueller, Wood, Willoughby, Ross, \& Specht, 2008). Students' science misconceptions are a commonplace and their performance is generally poor (Forsthuber, Motiejunaite, \& de Almeida-Coutinho, 2011). In primary level, many educational systems include modules related to the human anatomy and its organ systems. From the relevant literature, it is evident that students have difficulties in understanding how most of them function, including the respiratory (Mintzes, 1984; Tracana, Varanda, Viveiros, \& Carvalho, 2012) and the circulatory system (Allen, 2014; Gatt \& Saliba, 2006). In addition, it seems that students have trouble understanding the relationship between these two systems (Arnaudin \& Mintzes, 1985).

Taking into account the above, it was decided to examine whether the use of tablets can improve students' knowledge regarding the respiratory and circulatory systems. Towards this end, a study was designed and implemented, having as a target group primary school students. The main research hypothesis was that tablets together with a relevant application can yield better learning outcomes compared to conventional teaching. The paper is organized as follows. First, a brief review of the literature on the respiratory and the circulatory systems as teaching/learning subjects is presented, followed by a review of the literature on the educational use of tablets. Next, the project's methodology is analyzed, followed by results. Subsequently, results are discussed and the conclusion completes the work.

\section{The Respiratory and the Circulatory Systems as Teaching/Learning Subjects}

As mentioned in the introduction, in many countries the primary school's science curriculum includes units related to the human organ systems. For example, in Greece, the digestive system is taught in the fifth grade, while the respiratory and the circulatory systems are taught in the sixth (Hellenic Ministry of Education, 2011). In the UK, the circulatory system is also taught in the sixth grade (UK Department of Education, 2015). In Sweden, units related to human organs are included in grades four to six (Swedish National Agency for Education, 2011).

As for the problems that students face, it seems that several biological functions and phenomena are particularly difficult for them to grasp. This also applies to the way the organ systems function, probably because they are complex systems that interact with each other (Buckley, 2000). Also, students seem to find it hard to comprehend how the organs relate to each other, as they consider them as independent components of the body (Reiss \& Tunnicliffe, 2001).

Coming to the respiratory system, many students include irrelevant organs to this system such as the stomach (Garcia-Barros, Martínez-Losada, \& Garrido, 2011). The lungs are often placed in the upper part of the body (near the neck) and quite smaller than their actual size (Mintzes, 1984). Tracana et al. (2012) recorded several other students' misconceptions, such as the drawing of only one lung, of two lungs not related to each other, and of two lungs with two separate tracheas. Finally, students often feel that the air we inhale remains to our neck or head until we exhale (Allen, 2014). 
As for the circulatory system, the situation is similar since students have several misconceptions about the shape and function of the heart. For example, even though they often draw the correct size of the heart, it has the shape of the symbol of the heart (Gatt \& Saliba, 2006; Mintzes, 1984). The heart's internal structure it is often depicted with three cavities (atriums or ventricles) instead of four (Arnaudin \& Mintzes, 1985; Windschitl, 1995). The role of the heart is also misunderstood; students think that it produces or filters the blood (Ozgur, 2013). The circulatory system is regarded as a closed system; the amount of blood remains constant and the blood is moving in both directions inside the veins (Chi, Chiu \& DeLeeuw, 1991).

Finally, students seem to believe that the respiratory and the circulatory systems are not related to each other. In a study on how the blood flows into the body, the majority of students chose the model in which the blood flows from the heart to the extremities of the body and back to the heart, without including the circulation to the lungs (Windschitl, 1995).

\section{Tablets and Other Portable Devices in Education}

Sharples and Roschelle (2010) defined mobile learning as the way one can utilize mobile devices for educational purposes. Other definitions related to learning with the use of portable devices put emphasis on features like portability and wireless connectivity (Sad \& Goktas, 2014). Their relatively low cost has resulted in the proliferation of mobile learning (Haßler et al., 2015). It is strongly supported in the literature that mobile learning offers new educational experiences and opportunities for improving the learning process (e.g., Ferdousi \& Bari, 2015; Fokides \& Atsikpasi, 2017).

One of the main features of mobile learning is that it allows the framing of learning by the student (Clarke \& Svanaes, 2014; Ferdousi \& Bari, 2015). Thus, instruction becomes flexible and adaptable to many different learning styles and preferences (Rossing, Miller, Cecil, \& Stamper, 2012). In addition, mobile devices allow for what is called "ubiquitous learning", in which anyone can access curricular and other learning material anywhere and anytime (Murphy, 2011). Another important aspect of the use of mobile devices in education is that of blended learning, which brings together classroom teaching and mobile learning. The model of blended learning conglomerates the advantages of face-to-face teaching and distance learning, in order to create an effective learning environment for students (Chen, Huang \& Chou, 2017).

The use of tablets and smartphones also has a positive impact on students' motivation (AlMashaqbeh \& Al Shurman, 2015) and performance (Huang, Chen \& Ho, 2014). Moreover, collaborative learning is fostered with the use of tablets (Clarke \& Svanaes, 2014; Ferdousi \& Bari, 2015). That is because their use in teaching enhances the interaction and cooperation between students (Rossing et al., 2012).

On the other hand, there are some concerns regarding the use of tablets in teaching, with most of them being related to technical problems (e.g., the need for frequent charging of the devices and the small size of the screens) and problems with the software not being fully compatible with the curriculum (or largely inappropriate) (Fokides \& Atsikpasi, 2017). In addition, teachers expressed concerns that tablets can distract students as they tend to use them, during teaching, for purposes other than completing their tasks or studying (Sad \& Goktas, 2014; Wilkinson \& Barter, 2016). For that matter, teachers voiced objections to the use of tablets during teaching (Boticki, Baksa, Seow \& Looi, 2015; Domingo \& Garganté, 2016). Finally, the extent to which tablets are used in-classroom largely depends on how experienced the teachers are in the use 
of such devices, but also by the existence of an appropriate pedagogical framework for their use (Clarke \& Svanaes, 2014).

An interesting category of applications available for tablets and mobile devices is that of augmented reality (AR). AR is a technology that presents to the user, in real time, a combination of real and virtual objects (2D or $3 \mathrm{D}$ ), multimedia elements, and information, while allowing his/her interaction with the above (van Krevelen \& Poelman, 2010). The utilization of this technology in education opens new pathways which can enhance the effectiveness of teaching (Kesim \& Ozarslan, 2012) and make the learning process more attractive (Dunleavy, Dede, \& Mitchell, 2009) and interactive (Akcayir \& Akcayir, 2017). The use of AR in mobile learning promotes collaboration among students (Fulantelli, Taibi \& Arrigo, 2015). Furthermore, AR applications seem to enhance students' knowledge and skills (Safadel \& White, 2017). Since, in $A R$, the user can change the location, shape, and other characteristics of virtual objects, this can lead to a better understanding of concepts and systems, which in real life are impossible to observe, such as astronomy and the human anatomy (Billinghurst \& Dünser, 2012).

Focusing on the use of tablets and AR for the teaching of science courses, previous research has demonstrated that they can yield satisfactory results (Cheng \& Tsai, 2013; Sun, Looi, Wu \& Xie, 2016). It was found that AR applications enabled students to visualize and understand abstract scientific concepts and phenomena such as electromagnetism (Ibáñez, Di Serio, Villarán \& Kloos, 2014; Wu, Lee, Chang \& Liang, 2013). At the same time, the use of AR applications to simulate physics laboratories had positive results in the development of laboratory skills (Akcayir, Akcayir, Pektas, \& Ocak, 2016). In addition, positive results have been recorded when using AR in chemistry, for the visualization/3D representation of molecules and chemical reactions (Cai, Wang \& Chiang, 2014). The teaching of Astronomy (Fleck \& Simon, 2013) and Biology can also benefit (Crompton, Burke, Gregory, \& Gräbe, 2016). For example, Fokides kaı Atsikpasi (2017) used tablets and a commercial AR application to teach plants to primary school students; Chen et al. (2017) also used tablets and an AR application in blended learning settings for the same purpose. Also, tablets together with an application with 3D features were used for the teaching of the human anatomy, with equally interesting results (Wilkinson \& Barter, 2016).

\section{Method}

Given that tablets present an interesting alternative method for teaching science courses to primary school students, a study was implemented in order to examine what the learning outcomes of such an endeavor might be. The target group was sixth-grade primary school students (ages 11 to 12). The respiratory and circulatory systems were chosen as the teaching subjects, because, as presented in a previous section, in these two systems students face significant problems. A quasi-experimental design, with three participating groups, was selected because data from intact classrooms were analyzed for their differences in the learning results they had, as it will be further elaborated in the coming sections.

\section{Research Hypotheses}

The main objective of the study at hand was to examine whether tablets and a mobile application with AR features, can help students to better understand the functions of the respiratory and circulatory system, compared to conventional teaching methods. Students' 
views and attitudes towards the use of tablets were also considered important. Thus, the following research hypotheses were formed:

- H1: The use of tablets and of an application with 3D models and AR features, yields better learning outcomes, with respect to the human respiratory and circulatory systems, compared to conventional teaching methods.

- $\mathrm{H} 2$ : The retention of knowledge is also better.

- H3: Students form positive views and attitudes for their teaching using tablets.

\section{Participants and Duration of the Project}

As already mentioned, the target group was primary school students attending the sixth-grade. This age group was selected because, according to the Greek primary school curriculum, at this grade students are taught the respiratory and circulatory systems. An email invitation to participate in the project was issued, addressed to primary schools in Athens, Greece. The majority of schools which responded affirmatively had to be excluded because they were either too far apart or because they were private schools and the sample would be heterogeneous in terms of the socioeconomic status of students. Also, it was required that the students of the shortlisted schools: (a) should have never before used tablets as part of their teaching, (b) to reflect the spread of ability in a typical Greek sixth-grade class, and (c) the ratio of boys and girls to be close to that of a typical Greek primary school. The purpose of the above was to achieve an "ordinary" and "typical" sample (Creswell \& Poth, 2017).

Thus, a total of seventy-five students were recruited from three sixth-grade classes of three neighboring public primary schools and, to each class, an instructional method, described in the "Procedure" section, was randomly assigned. Students' parents were gathered and briefed about the project and they provided their written consent for their children's participation. Also, the teachers were briefed and they were asked to follow the teaching method that was assigned to them. The project lasted for about a month (four two-hour sessions in each class, from early March to mid-April 2017), as it was not implemented simultaneously to all schools.

\section{Materials}

An extensive search was conducted in order to find the most suitable application for the project. The relevant literature (e.g., Zydney \& Warner, 2016), as well as the project's specific needs, set the selection criteria. Thus, the application had: (a) to have AR features and 3D models, (b) the learning material to be scientifically correct and also compatible with students' mental capacity, (c) to be easy to use, (d) to provide a pleasant environment and graphics, (e) to include questions and tests for students' self-evaluation, and ( $f$ ) to highlight the relationship between the respiratory and circulatory systems. The search revealed several applications related to the human anatomy. However, most either focused on the visualization part providing a minimum amount of information or provided very complex information which exceeded, by far, that of primary school's level. Out of the shortlisted applications, Arloon's "The human body anatomy" (http://www.arloon.com) was deemed as the most suitable one (Figures 1-3). It has to be noted that the application's learning material is very similar to that of Greece's sixth-grade primary school textbooks for the science course. On the other hand, as in most applications, there was no Greek version. Thus, it was translated into Greek, with the permission of the developing company. This procedure lasted for about two months. 
For reasons that will be further elaborated in the coming section, a short handbook was written, which, in essence, was the transfer on paper of what was included in the application (texts and images). Also, a series of presentations were written. The application's, as well as the handbook's learning material, were organized into four two-hour units/sessions: (a) the organs of the human respiratory system and their functions, (b) the process of breathing, and the factors/habits associated with the healthy functioning of this system, (c) the organs of the circulatory system and their functions, and (d) the two types of blood circulation and the relationship between the respiratory and the circulatory system.

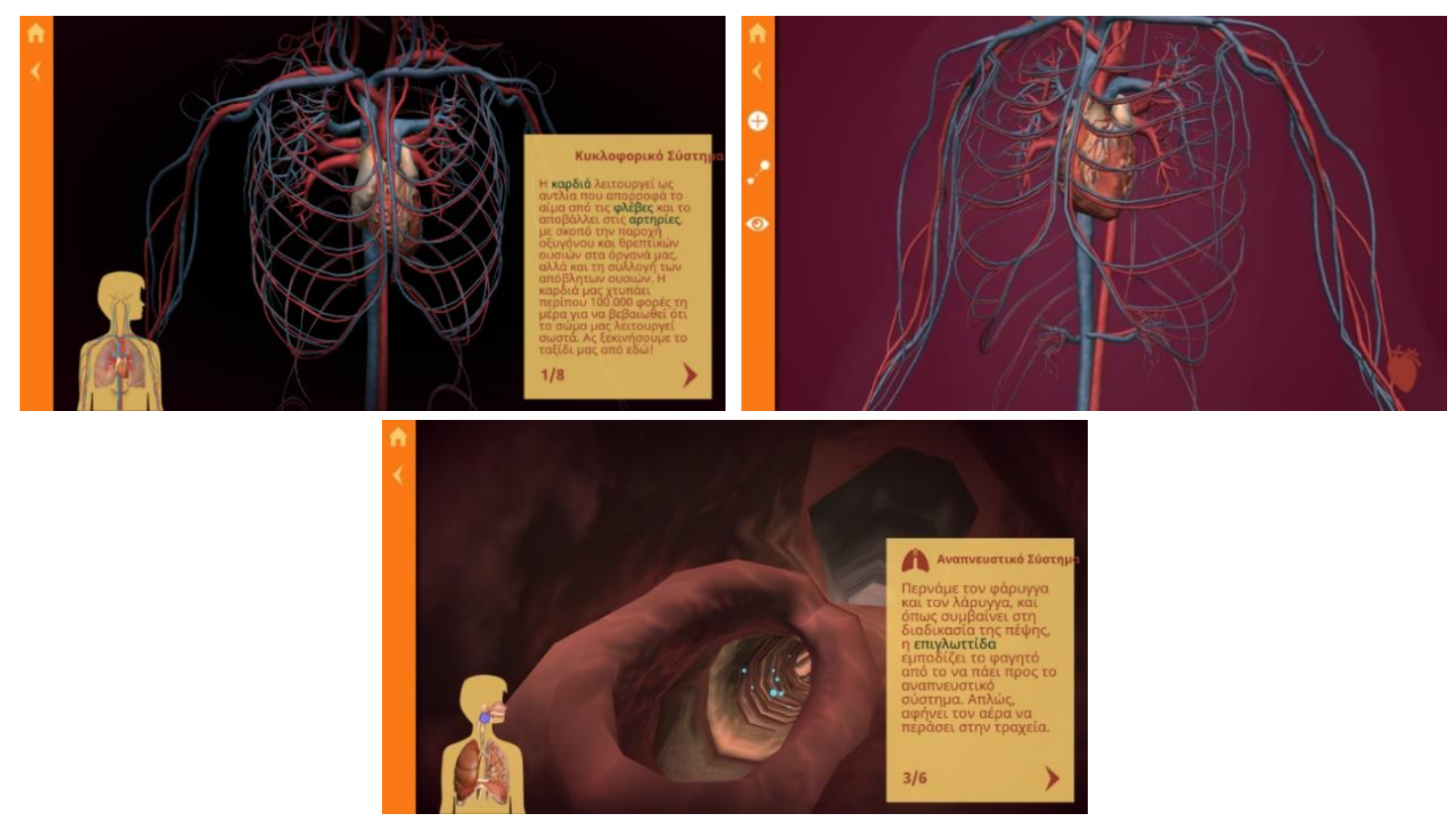

Figures 1-3. Sample Screenshots from the Application

\section{Procedures}

In the teaching of science courses, the literature suggests that students should work in small groups (Harlen \& Qualter, 2014). Consequently, it was decided students to work in pairs and each pair to have one tablet at its disposal. Students' active participation, increased autonomy, and control over their course of learning were also considered as essential (Clarke \& Svanaes, 2014; Wilkinson \& Barter, 2016). Thus, the teaching method that was followed was based on a slightly modified version (so as tablets could fit to the process) of Bybee's $5 E$ (Bybee et al., 2006). Accordingly, the teaching stages were: (a) a short introduction by the teacher, followed by short activities that their purpose was the engagement of students and the exploration of the new knowledge/concept, (b) use of the application for exploring and studying the relevant material, (c) application of new knowledge/concepts to everyday situations using worksheets, and (d) evaluation by completing the exercises included in the application. In each phase, students were free to discuss and collaborate. The teacher acted as a facilitator of the process by starting or joining in students' discussions, by drawing their attention to important aspects of their work, and by providing guidelines, but without giving away the solution to an exercise or enforcing his/her views. 
In order to compare the learning outcomes of the above teaching method, two more groups of students were formed. To the first, the teacher made a short introduction, followed by examples and/or presentations (using the class's video projector) regarding what students were about to learn. Next, students worked in pairs, by studying the relevant units in the textbooks. During this stage, the teacher's involvement was kept minimal; he/she did not intervene in students' work, discuss or collaborate with them. Only when needed, he/she paused students work in order to provide guidelines and examples to the whole class. Next, students completed the exercises (which were the same as in the application), presented the solutions to the exercises, and checked whether their answers were correct. This teaching method, with the exception of students working in pairs, is the prevailing one in Greece's schools.

The teaching of the second group was based on the constructivist teaching model (Driver \& Oldham, 1986). According to this model, there are five distinct stages of instruction: (a) in the setting the stage/orientation stage, an introductory discussion took place regarding the new knowledge/concept, accompanied by presentations (using the class's video projector), (b) during the elicitation stage, students worked in pairs discussed and recorded their views and ideas about the new subject, (c) in the restructuring stage the students studied the relevant units in the textbook, (d) in the review/implementation phase the students checked whether their initial views and ideas were correct and applied the new knowledge to new situations by working with worksheets, and (e) in the application/reflection stage, the students completed the textbook's exercises and discussed their answers. As in the tablets' group, the teacher's role -in all stages-was that of the facilitator of the process.

As a result, three groups of students were taught the same learning material and worked in pairs. Their only difference was the teaching method that was applied to each group, with one being technologically enhanced with the use of tablets. It has to be noted that, prior to the beginning of the project, in one one-hour session, the students who participated in the tablets group explored the affordances and constraints of these devices, without running the application, in order to proactively face any difficulties while using them.

\section{Instruments}

For data collection purposes, a total of six evaluation sheets were devised (pre- and delayed post-tests, and one for each of the four teaching units), consisting of multiple choice, yes-no, fillin-the-blanks, and open-ended questions. The pre- and delayed post-tests had a total of thirtyfive questions, while each of the evaluation sheets had twenty-five. All evaluation sheets were structured so as to apply two basic principles: (a) to fully cover the content of each unit, and (b) the questions were of escalating difficulty. Also, about half of the questions checked the knowledge that students acquired, while the other half checked whether they could apply this knowledge to everyday situations and required a certain degree of critical thinking.

A questionnaire for evaluating students' experiences and views regarding the use of tablets/application was also devised, consisting of two open-ended and fifteen five-point Likerttype questions (worded "Strongly Agree", "Agree", "Neutral", "Disagree" and "Strongly Disagree"). Scores were obtained by allocating numerical values to responses: "Strongly Agree" scored 5, "Agree" scored 4; "Neutral" scored 3; "Disagree" scored 2 and "Strongly Disagree" scored 1. 


\section{Results}

As presented in the preceding section, the study's sample (seventy-five students) was divided into three groups of equal size: Group1 conventional teaching, Group2 constructivist teaching, and Group3 tablets group. The distribution of boys and girls in all groups was approximately the same. Scores in all the evaluation sheets (including the pre- and delayed post-tests) were computed on the basis of the number of correct answers. Mean scores and standard deviations per group of participants and per evaluation sheet are presented in Table 1.

Table 1. Means and standard deviations per group and per evaluation sheet

\begin{tabular}{lcccccc}
\hline & \multicolumn{9}{c}{ Group } \\
& \multicolumn{2}{c}{ Group1 } & \multicolumn{2}{c}{ Group2 } & \multicolumn{2}{c}{ Group3 } \\
& $M$ & $(N=25)$ & \multicolumn{2}{c}{$(N=25)$} & \multicolumn{2}{c}{$(N=25)$} \\
Pre-test $40(\max =35)$ & 15.16 & 4.06 & 15.80 & 3.23 & 16.32 & 3.06 \\
ES1 $(\max =25)$ & 14.16 & 3.76 & 15.88 & 3.59 & 17.92 & 2.20 \\
ES2 $(\max =25)$ & 14.86 & 3.45 & 16.70 & 3.87 & 17.68 & 2.60 \\
ES3 $(\max =25)$ & 14.36 & 3.87 & 15.64 & 3.98 & 16.64 & 3.05 \\
ES4 $(\max =25)$ & 12.84 & 3.27 & 14.72 & 4.62 & 17.80 & 1.91 \\
Delayed post-test $(\max =35)$ & 21.40 & 7.90 & 26.44 & 5.14 & 30.68 & 3.61 \\
\hline
\end{tabular}

Note. ES = Evaluation sheet

One-way ANOVA tests were to be conducted to compare the scores of the three groups, in order to determine if they had any statistically significant differences. Prior to conducting these tests, it was checked whether the assumptions for ANOVA testing were violated. It was found that: (a) all groups had the same number of participants $(N=25)$, (b) there were no outliers, (c) the data were not normally distributed in all tests, as assessed by Q-Q plots and the Shapiro-Wilk test, and (d) the homogeneity of variance was violated in some cases, as assessed by Levene's Test of Homogeneity of Variance.

Given that the data were not normally distributed and, in some cases, the homogeneity of variance was violated, it was decided to proceed using the Kruskal-Wallis $\mathrm{H}$ test, which is a nonparametric test. Although this test does not require normally distributed data, it requires similarly shaped data distributions (Corder \& Foreman, 2009), as was the case in all the evaluation sheets. The tests revealed that:

- There were no statistically significant differences in:

○ Pre-test, $H(2)=0.975, p=0.614$

$\circ \mathrm{ES} 3, H(2)=4.30, p=0.109$

- The mean rank scores of the three groups of students had statistically significant differences in:

$$
\begin{array}{ll}
\circ & \text { ES1, } H(2)=14.18 . p=0.001 \\
\circ & \text { ES2, } H(2)=7.91 . p=0.019 \\
\circ & \text { ES4, } H(2)=24.25 . p<0.001 \\
\circ \quad \text { Delayed post-test, } H(2)=21.30 . p<0.001
\end{array}
$$

Post-hoc comparisons on all possible pairwise contrasts were conducted in the evaluations sheets where statistically significant differences were noted, using the Bonferroni approach (controlling for Type I errors) (Dunn, 1964). It was found that: 
- ES1. Group3 (mean rank score $=29.96)$ fared better than Group2 (mean rank score $=21.04)$, $(U=201.00, Z=-2.19, p=0.028)$ and the effect size was medium $(r=-0.31)$. Also, Group3 (mean rank score $=32.98$ ) fared better than Group1 (mean rank score $=18.02),(U=125.50$, $Z=-3.67, p<0.001)$ and the effect size was large $(r=-0.52)$. Groups 1 and 2 did not have any statistically significant difference, $(U=224.00, Z=-1.73, p=0.084)$.

- ES2. Groups 2 and 3 did not have any statistically significant differences, $(U=279.00, Z=-$ $0.66, p=0.510$ ). On the other hand, Group2 (mean rank score $=31.26$ ) fared better than Group1 (mean rank score $=19.74),(U=168.50, Z=-2.82, p=0.005)$ and the effect size was medium $(r=-0.40)$. Also, Groups 1 and 2 did not have any statistically significant differences, $(U=217.50, Z=-1.85, p=0.064)$.

- ES4. Group3 (mean rank score $=30.34$ ) fared better than Group2 (mean rank score $=20.66$ ), $(U=191.50, Z=-2.38, p=0.017)$ and the effect size was medium $(r=-0.34)$. Also, Group3 (mean rank score $=35.96)$ fared better than Group1 (mean rank score $=15.04)$, $(U=51.00$, $Z=-5.12, p<0.001$ ) and the effect size was large $(r=-0.72)$. Group2 (mean rank score $=$ 29.88 ) fared better than Group1 (mean rank score $=21.12),(U=203.00, Z=-2.14, p=0.033$ ) and the effect size was medium $(r=-0.30)$.

- Delayed post-test. Group3 (mean rank score $=31.76$ ) fared better than Group2 (mean rank score $=19.24),(U=156.00, Z=-3.05, p=0.002)$ and the effect size was medium $(r=-0.43)$. Also, Group3 (mean rank score $=34.04$ ) fared better than Group1 (mean rank score $=16.96)$, $(U=99.00, Z=-4.16, p<0.001)$ and the effect size was large $(r=-0.59)$. Group2 (mean rank score $=30.44)$ fared better than Group1 (mean rank score $=20.56),(U=189.00, Z=-2.40, p$ $=0.016)$ and the effect size was medium $(r=-0.34)$.

In summary, the above results confirm $\mathrm{H} 1$ and $\mathrm{H} 2$ because:

- The three groups had the same initial knowledge level regarding the respiratory and the circulatory systems, given that in the Pre-test there were no statistically significant differences. Therefore, any differences found in the evaluation sheets can be attributed to the different teaching methods.

- In Evaluation Sheet 1 (the organs of the respiratory system), Group 3 surpassed the other two groups, but no statistically significant difference was noted between groups 2 and 1 .

- In Evaluation Sheet 2 (the process of respiration), the only statistically significant difference that was noted was between groups 3 and 1, with Group 3 having better learning outcomes.

- In Evaluation Sheet 3 (the organs of the circulatory system) no statistically significant differences were noted. Therefore, the teaching methods, in this case, did not have an impact on the learning outcomes.

- In Evaluation Sheet 4 (blood circulation and the link between the respiratory and the circulatory system) as well as in the Delayed post-test, Group3 surpassed the other two groups and, also, Group2 surpassed Group 1.

- In all cases the effect sizes between Group3 and Group1 were large, the effect sizes between Group3 and Group2 were medium, and the effect sizes between Group2 and Group1 were also medium.

Students' strong positive attitude towards the use of tablets was evident in most of their responses (Table 2), thus, $\mathrm{H} 3$ (students form positive views and attitudes for their teaching using tablets) was confirmed. Also, collaboration seems to have worked well $(M=4.30, S D=.45)$ and 
students acknowledged how important their partner was in the development of their games ( $M$ $=4.40, S D=.55$ ).

Table 2. Results in Students' Questionnaire

\begin{tabular}{ll}
\hline \multicolumn{1}{c}{ Question } & $M(S D)$ \\
\hline 1. I collaborated with my fellow student nicely. & $4.30(.45)$ \\
2. I feel that working as a pair helped me to learn. & $4.40(.55)$ \\
3. I think that using tablets during the lesson is boring.* & $4.11(.81)$ \\
4. I think that using tablets during the lesson is an enjoyable activity. & $4.60(.70)$ \\
5. Working with tablets was fun. & $4.48(.77)$ \\
6. I enjoyed working with tablets. & $4.36(.86)$ \\
7. Working with tablets made me want to learn more about the human & $3.94(.70)$ \\
& \\
8. I was eager to conduct the project's lessons. & $4.14(.90)$ \\
9. I found the courses very interesting & $4.21(.67)$ \\
10. I do not feel that I have learned anything*. & $3.81(.44)$ \\
11. I believe that the application was like a game & $4.16(.31)$ \\
12. Working with tablets was difficult.* & $4.52(.71)$ \\
13. I did not like the courses at all.* & $4.30(.51)$ \\
14. I would like to use tablets again in my teaching & $4.42(.55)$ \\
15. It would be nice to use tablets in all lessons/courses & $4.80(.58)$ \\
\hline
\end{tabular}

Notes: * indicates a question for which its scoring was reversed; standard deviations are reported in parentheses

The two open-ended questions were about what students liked and what problems they faced. It seems that they liked many, if not all, of the application's features; the augmented reality features (overlaying 3D models in real people/students) $(N=24)$, the 3D models $(N=23)$, the 3D animations $(N=23)$, and the way the information was presented to them $(N=19)$. No significant problems were reported regarding the use of either the tablets or the application with the exception of some students having trouble triggering the augmented reality features. These problems were eased after some practicing.

\section{Discussion}

The data analysis, as presented in the preceding section, revealed that the performance of students who were taught with a contemporary teaching method together with the use of tablets, exceeded that of students who were taught conventionally (in four out of five cases) and of students who were taught with a constructivist method (in three out of five cases). These results are in agreement with previous studies, which compared conventional teaching with teaching using tablets (e.g., Fokides \& Atsikpasi, 2017; Furió, Juan, Seguí \& Vivó, 2015).

A series of factors might have contributed to this outcome. Motivation for learning and students' active involvement in the learning processes are two of them. Literature suggests that when using tablets students are more motivated and more engaged in the learning process, (e.g., Zydney \& Warner, 2016). Moreover, students' positive attitude towards an ICT tool, namely tablets, allows the successful utilization of this tool in teaching (Chen et al., 2017; Furió et al., 2015). The present study confirms these views. Indeed, students stated that they enjoyed 
working with tablets (see questions three through six) and that they felt motivated (see questions seven through nine). Also, an indication of students' positive attitude comes from questions thirteen through fifteen.

The learning theory that framed the project was constructivism and the teaching method was based on Bybee's 5E (Bybee et al., 2006). Both embrace students' collaboration and active learning. Previous studies suggested that students' collaboration is fostered when they use tablets during teaching (Clarke \& Svanaes, 2014; Rossing et al., 2012). At the same time, the teaching was a combination of classroom instruction and mobile learning. According to the relevant literature, blended learning seems to have a positive impact on the learning process (Chen, et al., 2017). The findings of the present study give support to this view. Students' responses to the relevant questions indicated increased levels of collaboration (see Question1) and that they acknowledged the contribution of their partner in their learning (see Question2).

Students also liked that they were having fun and, at the same time, they were learning (see questions five, six, ten, and eleven). It is strongly supported in the literature that tablets together with applications having AR features make the learning process more fun (e.g., Akcayir \& Akcayir, 2017; Dundar \& Akcayir, 2014). Fun and enjoyment, when using these devices, also act as facilitators of the learning process (Fulantelli et al., 2015).

It is also quite logical to assume that the application reinforced what is called "empirical learning" (Chen, et al., 2017). That is because it presented all the human organs using 3D models, allowing students to zoom in and out and study them from multiple perspectives. Also, the application included 3D animations for a number of organ functions (e.g., breath and blood circulation). Researchers view these features as enhancements in students' learning experience (Al-Mashaqbeh \& Al Shurman, 2015). The better visualization, compared to the other methods, probably led to the better understanding of how these organs function, and, consequently, to better students' performance (Dunleavy et al., 2009; Fitzgerald, Taylor \& Craven, 2013). In addition, the interactive texts and information probably had a positive impact on students' performance too (Alyahya \& Gall, 2012). Literature suggests that the detailed visualization of a learning subject/concept also has an impact on students' long-term retention of knowledge (Ferdousi \& Bari, 2015). This might explain why students in Group3 had better performance in the Delayed post-test.

In addition, students were able to study the material included in the application at their own pace. At any time, they could take the self-assessment tests, read the information, and study the organs. To put it differently, students were responsible and in control of their learning. The connection between students' increased autonomy and positive learning outcomes has been noted by other researchers (Boticki et al., 2015; Ferdousi \& Bari, 2015; Wilkinson \& Barter, 2016).

Finally, no problems were noted regarding the use of tablets, and students, in their majority, stated that their use did not cause them any trouble. This implies that tablets are compatible with students' ICT skills (Gorhan et al., 2014).

The study's results have implications for educators as well as for software developers. An issue that had to be dealt at the early stages of the project was that of finding and using a suitable application. Although a wealth of relevant applications was found, few were considered as suitable for educational purposes. Out of these few, even fewer were appropriate (in terms of the complexity of the learning material) for primary school students. This fact highlights the 
need for collaboration between software engineers and educators as Shuler, Levine, and Ree (2012) suggested. The former, though experts in software design, do not have the necessary educational background that could render them adept designers of instructional applications. The later, although they can set the guidelines, are not aware of technology's affordances and limitations. Close collaboration between the two groups of experts can only bring benefits to students who are the end users of ICT tools and applications.

The study's results can also lead to a number of recommendations to education administrators and policymakers. Students' positive attitude towards the use of tablets in teaching paired with the satisfactory learning outcomes (at least for the subjects that were examined in the present study), renders their educational exploitation an idea that has to be taken into serious consideration. Also, tablets seem to have a positive effect when their use is framed with a contemporary teaching method, for example, Bybee's $5 \mathrm{E}$. Since the above method was not formed having tablets in mind, modifications had to be made in order to implement it. Thus, the study's proposed method can provide a good starting point for the formulation of teaching methods that could utilize the full potential of tablets. Finally, time is a critical factor. Students need to have enough time at their disposal so as to use tablets at their own pace. This was the underline reason for allocating two teaching hours per session. Consequently, the primary school's curriculum and the hours allocated for subjects in which tablets are going to be used have to be to be reconsidered.

\section{Conclusion}

Despite the interesting results, the study has limitations that need to be acknowledged. The sample (75 students), though sufficient for statistical analysis it was relatively small; therefore, the generalizability of the results is questionable. At the same time, the number of teaching interventions was limited, due to the subjects that were taught and also because of restrictions imposed by the schools, which resulted in the short duration of the project. The questionnaire measuring students' views and experiences when using tablets was very short. A more comprehensive one would have enabled the collection of more detailed data. Lastly, a questionnaire and evaluation sheets were used for data collection purposes; other means, such as interviews and observations, would have allowed a more in-depth analysis.

Future studies can be conducted having larger sample sizes and/or in different age groups and levels of education. In addition, future projects can have, as a teaching/learning subject, other organ systems of the human body. A very interesting topic is the examination of students' misconceptions regarding the organ systems and if they can be eased with the use of tablets. Finally, comparisons between tablets and other ICT tools and applications (e.g., laptops and virtual reality) can provide a clearer picture of the benefits that tablets can bring to education.

In any case, and despite the limitations of the study, it can be concluded that tools like the tablets, combined with applications with augmented reality features, provide an interesting alternative method for teaching the human anatomy to primary level. Students were more engaged in the learning process, increased levels of collaboration were noted, and the learning outcomes were good, compared to the other teaching methods. On the other hand, the software industry has to work closely with educators in order the later to have at their disposal more -and pedagogically sound- applications for their teaching. Also, new teaching methods have to be devised. Therefore, there is still a long way ahead before the full potential of tablets and their impact on pedagogy is realized. 


\section{References}

Akcayir, M, \& Akcayir, G. (2017). Advantages and challenges associated with augmented reality for education: a systematic review of the literature. Educational Research Review, 20, 111. https://doi.org/10.1016/j.edurev.2016.11.002

Akcayir, M., Akcayir, G., Pektas, H. M., \& Ocak, M. A. (2016). Augmented reality in science laboratories: The effects of augmented reality on university students' laboratory skills and attitudes toward science laboratories. Computers in Human Behavior, 57, 334-342. https://doi.org/10.1016/j.chb.2015.12.054

Allen, M. (2014). Misconceptions in primary science. Berkshire, UK: Open University Press.

Al-Mashaqbeh, I., \& Al Shurman, M. (2015). The adoption of tablet and e-textbooks: first grade core curriculum and school administration attitude. Journal of Education and Practice, 6(21), 188-194.

Alyahya, S. \& Gall, J. E. (2012). iPads in education: A qualitative study of students' attitudes and experiences. In T. Amiel, \& B. Wilson (Eds.), Proceedings of EdMedia: World Conference on Educational Media and Technology 2012 (pp. 1266-1271). Chesapeake, VA: AACE.

Arnaudin, M. W. \& Mintzes, J. J. (1985). Students' alternative conceptions of the human circulatory system: A cross-age study. Science Education, 69(5), 721-733. https://doi.org/10.1002/sce.3730690513

Billinghurst, M. \& Dunser, A. (2012). Augmented reality in the classroom. Computer, 45(7), 5663. doi: 10.1109/MC.2012.111

Boticki, I., Baksa, J., Seow, P., \& Looi, C-K. (2015). Usage of a mobile social learning platform with virtual badges in a primary school. Computers \& Education, 86, 120-136. https://doi.org/10.1016/j.compedu.2015.02.015

Buckley, B. C. (2000). Interactive multimedia and model-based learning in biology. International Journal of Science Education, 22(9), 895-935. https://doi.org/10.1080/095006900416848

Bybee, R. W., Taylor, J. A., Gardner, A., Van Scatter, P., Carlson-Powell, J., Westbrook, A., \& Landes, N. (2006). BSCS SE instructional model: Origins and effectiveness. A report prepared for the Office of Science Education, National Institutes of Health. Colorado Springs, CO: BSCS.

Cai, S., Wang, X., \& Chiang, F-K. (2014). A case study of augmented reality simulation system application in a chemistry course. Computers in Human Behavior, 37, 31-40. https://doi.org/10.1016/j.chb.2014.04.018

Chen, C-H., Huang, C-Y., \& Chou, Y-Y. (2017). Integrating augmented reality into blended learning for elementary science course. Proceedings of the 5th International Conference on Information and Education Technology, 68-72. New York, NY: ACM. https://doi.org/10.1145/3029387.3029417

Cheng, K-H. \& Tsai, C-C. (2013). Affordances of augmented reality in science learning: suggestions for future research. Journal of Science Education and Technology, 22(4), 449-462. https://doi.org/10.1007/s10956-012-9405-9

Chi, M. T. H., Chiu, M., \& DeLeeuw, N. (1991). Learning in a non-physical science domain: The human circulatory system. Pittsburgh, PA: Learning Research and Development Center. 
Clarke, B. \& Svanaes, S. (2014). Tablets for schools: an updated literature review on the use of tablets in education. Retrieved on 16 September 2017 from http://maneele.drealentejo.pt/site/images/Literature-Review-Use-of-Tablets-inEducation-9-4-14.pdf

Corder, G. W. \& Foreman, D. I. (2009). Nonparametric statistics for non-statisticians: A step-bystep approach. John Wiley \& Sons. https://doi.org/10.1002/9781118165881

Creswell, J. W. \& Poth, C. N. (2017). Qualitative inquiry and research design: Choosing among five approaches. Sage Publications.

Crompton, H., Burke, D., Gregory, K. H., \& Gräbe, C. (2016). The use of mobile learning in science: a systematic review. Journal of Science Education and Technology, 25(2), 149160. https://doi.org/10.1007/s10956-015-9597-x

Domingo, M. G. \& Garganté, A. B. (2016). Exploring the use of educational technology in primary education: Teachers' perception of mobile technology learning impacts and applications' use in the classroom. Computers in Human Behavior, 56, 21-28. https://doi.org/10.1016/j.chb.2015.11.023

Driver, R. \& Oldham, V. (1986). A constructivist approach to curriculum development in science. Studies in Science Education, 13(1), 105-122. https://doi.org/10.1080/03057268608559933

Dundar, H. \& Akcayir, M. (2014). Implementing tablet PCs in schools: Students' attitudes and opinions. Computers in Human Behavior, 32, 40-46. https://doi.org/10.1016/j.chb.2013.11.020

Dunleavy, M., Dede, C., \& Mitchell, R. (2009). Affordances and limitations of immersive participatory augmented reality simulations for teaching and learning. Journal of Science Education and Technology, 18(1), 7-22. https://doi.org/10.1007/s10956-008-9119-1

Dunn, O. J. (1964). Multiple comparisons using rank sums. Technometrics, 6, 241-252. doi: 10.1080/00401706.1964.10490181

Ferdousi, B. \& Bari, J. (2015). Infusing mobile learning into undergraduate courses for effective learning. Procedia-Social and Behavioral Sciences, 176, 307-311. https://doi.org/10.1016/j.sbspro.2015.01.476

Fitzgerald, E., Taylor, C., \& Craven, M. (2013). To the Castle! A comparison of two audio guides to enable public discovery of historical events. Personal and Ubiquitous Computing, 17(4), 749-760. https://doi.org/10.1007/s00779-012-0624-0

Fleck, S. \& Simon, G. (2013). An augmented reality environment for astronomy learning in elementary grades: an exploratory study. Proceedings of the 25th Conference on I'Interaction Homme-Machine, 14-22. New York, NY: ACM. https://doi.org/10.1145/2534903.2534907

Fokides, E. \& Atsikpasi, P. (2017). Tablets in education. Results from the initiative ETiE, for teaching plants to primary school students. Education and Information Technologies, 22(5), 2545-2563. https://doi.org/10.1007/s10639-016-9560-3

Forsthuber, B., Motiejunaite, A., \& de Almeida-Coutinho, A. S. (2011). Science education in Europe: National policies, practices and research. Education, Audiovisual and Culture Executive Agency, European Commission. 
Fulantelli, G., Taibi, D., \& Arrigo, M. (2015). A framework to support educational decision making in mobile learning. Computers in Human Behavior, 47, 50-59. https://doi.org/10.1016/j.chb.2014.05.045

Furió, D., Juan, M-C., Seguí, I., \& Vivó, R. (2015). Mobile learning vs. traditional classroom lessons: a comparative study. Journal of Computer Assisted Learning, 31(3), 189-201. https://doi.org/10.1111/jcal.12071

Garcia-Barros, S., Martínez-Losada, C., \& Garrido, M. (2011). What do children aged four to seven know about the digestive system and the respiratory system of the human being and of other animals? International Journal of Science Education, 33(15), 2095-2122. https://doi.org/10.1080/09500693.2010.541528

Gatt, S. \& Saliba, M. (2006). Young children's ideas about the heart. In M. F. Costa, \& B. V. Dorrío (Eds.), Proceedings of the $3^{\text {rd }}$ International Conference on Hands-on Science. Science Education and Sustainable Development, 17-23.

Gorhan, M. F., Oncu, S., \& Senturk, A. (2014). Tablets in education: Outcome expectancy and anxiety of middle school students. Educational Sciences: Theory and Practice, 14(6), 2259-2271.

Haßler, B., Major, L., \& Hennessy, S. (2015). Tablet use in schools: a critical review of the evidence for learning outcomes. Journal of Computer Assisted Learning, 32(2), 139-156. doi: $10.1111 /$ jcal.12123

Harlen, W. \& Qualter, A. (2014). The teaching of science in primary schools (6th ed.). Routledge.

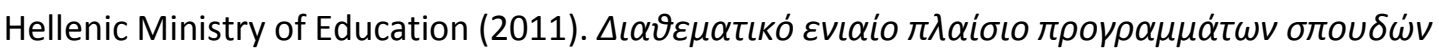
[Unified curricular framework]. Retrieved on 16 September 2017 from http://www.pischools.gr/programs/depps/

Huang, K-L., Chen, K-H., \& Ho, C-H. (2014). Enhancing learning outcomes through new etextbooks: a desirable combination of presentation methods and concept maps. Australasian Journal of Educational Technology, 30(5), 600-618. https://doi.org/10.14742/ajet.538

Ibáñez, M. B., Di Serio, Á., Villarán, D., \& Kloos, C. D. (2014). Experimenting with electromagnetism using augmented reality: Impact on flow student experience and educational effectiveness. Computers \& Education, 71, 1-13. https://doi.org/10.1016/j.compedu.2013.09.004

Kesim, M. \& Ozarslan, Y. (2012). Augmented reality in education: current technologies and the potential for education. Procedia-Social and Behavioral Sciences, 47, 297-302. https://doi.org/10.1016/j.sbspro.2012.06.654

Mang, C. F. \& Wardley, L. J. (2013). Student perceptions of using tablet technology in postsecondary classes. Canadian Journal of Learning and Technology, 39(4), 1-16.

Mintzes, J. J. (1984). Naïve theories in biology: Children's concepts of the human body. School Science and Mathematics, 84(7), 548-555. https://doi.org/10.1111/j.19498594.1984.tb10179.x

Mueller, J., Wood, E., Willoughby, T., Ross, C., \& Specht, J. (2008). Identifying discriminating variables between teachers who fully integrate computers and teachers with limited integration. Computers \& Education, 51(4), 1523-1537. https://doi.org/ 10.1016/j.compedu.2008.02.003 
Murphy, G. D. (2011). Post-PC devices: A summary of early iPad technology adoption in tertiary environments. E-Journal of Business Education \& Scholarship of Teaching, 5(1), 18-32.

Ozgur, S. (2013). The persistence of misconceptions about the human blood circulatory system among students in different grade levels. International Journal of Environmental \& Science Education, 8(2), 255-268. https://doi.org/10.12973/ijese.2013.206a

Reiss, M. J. \& Tunnicliffe, S. D. (2001). Students' understandings of human organs and organ systems. Research on Science Education, 31(3), 383-399. https://doi.org/10.1023/A:1013116228261

Rossing, J. P., Miller, W. M., Cecil, A. K., \& Stamper, S. E. (2012). iLearning: The future of higher education? Student perceptions on learning with mobile tablets. Journal of the Scholarship of Teaching and Learning, 12(2), 1-26.

Sad, S. N. \& Goktas, Ö. (2014). Preservice teachers' perceptions about using mobile phones and laptops in education as mobile learning tools. British Journal of Educational Technology, 45(4), 606-618. https://doi.org/10.1111/bjet.12064

Safadel, P. \& White, D. (2017). A comparative analysis of augmented reality and twodimensional using molecular modeling on student learning. In P. Resta, \& S. Smith (Eds.), Proceedings of Society for Information Technology \& Teacher Education International Conference 2017 (pp.1774-1776). Chesapeake, VA: AACE.

Sharples, M. \& Roschelle, J. (2010). Guest editorial: Special issue on mobile and ubiquitous technologies for learning. IEEE Transactions on Learning Technologies, 3(1), 4-6. https://doi.org/ 10.1109/TLT.2010.7

Shuler, C., Levine, Z., \& Ree, J. (2012, January). iLearn II: An analysis of the education category of Apple's app store. New York: The Joan Ganz Cooney Center at Sesame Workshop.

Sun, D., Looi, C-K., Wu, L., \& Xie, W. (2016). The innovative immersion of mobile learning into a science curriculum in Singapore: an exploratory study. Research in Science Education, 46(4), 547-573. https://doi.org/10.1007/s11165-015-9471-0

Swedish National Agency for Education. (2011). Curriculum for the compulsory school, preschool class and the recreation centre. Retrieved on 16 September 2017 from https://www.skolverket.se/om-skolverket/publikationer/visa-enskildpublikation?_xurl_=http\%3A\%2F\%2Fwww5.skolverket.se\%2Fwtpub\%2Fws\%2Fskolbok\% 2Fwpubext\%2Ftrycksak\%2FBlob\%2Fpdf2687.pdf\%3Fk\%3D2687

Tracana, R. B., Varanda, I., Viveiros, S., \& Carvalho, G. S. (2012). Children's conceptions about respiration before and after formal teaching: identification of learning obstacles. Proceedings of the XV IOSTE Symposium (International Organization for Science and Technology Education)-The use of Science and Technology Education for Peace and Sustainable Development, 1-11.

UK Department of Education. (2015). National curriculum in England: science programmes of study. Retrieved on 16 September 2017 from https://www.gov.uk/government/ publications/national-curriculum-in-england-science-programmes-of-study/nationalcurriculum-in-england-science-programmes-of-study\#key-stage-3

van Krevelen, D. W. F. \& Poelman, R. (2010). A survey of augmented reality technologies, applications and limitations. The International Journal of Virtual Reality, 9(2), 1-20.

Wilkinson, K. \& Barter, P. (2016). Do mobile learning devices enhance learning in higher education anatomy classrooms? Journal of Pedagogic Development, 6(1), 14-23. 
Windschitl, M. A. (1995). Using computer simulations to enhance conceptual change: the roles of constructivist instruction and student epistemological beliefs. Retrospective Theses and Dissertations (Paper 15946). Retrieved on 16 September 2017 from http://lib.dr.iastate.edu/cgi/viewcontent.cgi?article=16945\&context=rtd

Wu, H-K., Lee, S. W-Y., Chang, H-Y., \& Liang, J-C. (2013). Current status, opportunities and challenges of augmented reality in education. Computers \& Education, 62, 41-49. https://doi.org/ 10.1016/j.compedu.2012.10.024

Zydney, J. M. \& Warner, Z. (2016). Mobile apps for science learning: Review of research. Computers \& Education, 94, 1-17. https://doi.org/10.1016/j.compedu.2015.11.001

Correspondence: Emmanuel Fokides, Assistant Professor, Department of Primary School Education, University of the Aegean, , Rhodes, Greece 